\title{
Assessing the global distribution of river fisheries harvest: a systematic map protocol
}

\author{
Chelsie L. Romulo ${ }^{1,2,3^{*}}$ (D) Zeenatul Basher ${ }^{2,4}$, Abigail J. Lynch², Yu-Chun Kao ${ }^{4,5}$ and William W. Taylor ${ }^{4}$
}

\begin{abstract}
Background: Although surface freshwater comprises $<0.01 \%$ of the total water volume of earth, freshwater inland capture fisheries and aquaculture represent $40 \%$ of the global reported finfish harvest. While the social, economic, and ecological importance of inland fish and fisheries is difficult to overstate, they are often undervalued and underappreciated. Accurate information about these highly dispersed fisheries is inherently difficult to acquire, often unreported, and not collected in a standardized format globally. A standardized river fishery database is needed for managing aquatic systems as well as for defining relevant development policies. Here, we describe our methodology to search, identify, and describe available river fisheries information to create a harmonized global database of river fisheries harvest. This database will provide the first global database of spatially and temporally explicit river fisheries data. The database can be used to identify locations, hotspots of data collection, and gaps in existing knowledge and will be especially important to inform studies and management at larger spatial scales (i.e., watershed, regional, or global scales). This database will also be critical for developing fish biomass models for rivers, which can provide managers with information critical for decision-making, such as improved valuation methods for river fish and fisheries.

Methods: This systematic map protocol describes the methodology to search, identify, and describe available information on river fish and fisheries across the globe. We define river fisheries as "both capture and aquaculture of river finfish species for food, income, or recreation". River fish species are those finfish that live part, or all of their lives in rivers. The searches will be conducted for the period from 1950 to present using bibliographic databases and grey literature sources. To identify relevant evidence, pre-defined inclusion and exclusion criteria will be used to screen articles at title, abstract, and full text. A searchable database containing extracted meta-data from relevant included studies will be developed and presented as a geodatabase. The final systematic map will consist of a descriptive narrative report of the distribution and content of river fish literature including a geodatabase of available information.
\end{abstract}

Keywords: Freshwater fish, Inland fish, Aquatic ecosystems, Watersheds, Spatial distribution, Global, Map, Limnology, River Basin

\section{Background}

River fisheries, defined as both capture and aquaculture of river fish species for food, income, or recreation contribute substantially to meeting challenges faced by individuals, society, and the environment in a changing global landscape $[1,2]$. For example, in the Lower Mekong Basin, $80 \%$ of the 60 million inhabitants directly

\footnotetext{
*Correspondence: cromulo@masonlive.gmu.edu;

Chelsie.Romulo@unco.edu

${ }^{3}$ Environmental and Sustainability Studies Program, University

of Northern Colorado, 501 20th St., Greeley, CO 80639, USA

Full list of author information is available at the end of the article
}

rely upon the river fisheries for food and livelihoods [3]. Additionally, with upwards of 1700 fish species, the Mekong River is a global 'hotspot' of fish biodiversity [4], so understanding the relationship between the human fisheries system and the natural ecological system is critical for maintaining both the biodiversity of the resident fishes and well-being of the local human communities in the area. While the social, economic, and ecological importance of inland fish and fisheries is difficult to overstate, they are often undervalued and underappreciated [5]. This is due to the fact that accurate information about these highly dispersed fisheries is inherently 
difficult to acquire, often unreported, and not collected in a standardized format globally $[6,7]$. Consequently, these fisheries are often given low priority in planning and policy discussions relative to other uses of river ecosystem services such as drinking water, agriculture, or energy production $[5,8]$.

Data related to riverine fisheries are not collected in any standardized format globally [9] and thus the extent and distribution of these fisheries has never been adequately assessed in aggregate. Targeted analyses have been conducted on certain river systems such as the Mekong $[10,11]$, or regions such as Southeast Asia [12] but the approaches (e.g., consumption surveys, intensive field sampling) would not be feasible at a global scale due to the cost and effort involved [13]. Most river fisheries are highly diffuse and small-scale in nature and in areas lacking necessary infrastructure for regular reporting, so the data collection that is occurring is generally not systematically distributed, but instead tend to be focused in the most developed countries [14]. Understanding the catch trends and predictions of river fisheries harvests is critical for the future of stakeholders who depend on these systems for food and livelihoods, but these fisheries harvests have not yet been quantitatively assessed at the global level in the ways that marine fisheries have been $[15,16]$.

The proposed systematic map protocol will provide a database of river fish harvest and assessment of available data. This study will also provide the first spatially and temporally located systematic map of river fisheries data regarding what species are fished, how much fish are being fished, and how those fish are being removed from river systems (for a systematic review of marine fisheries, see Chassot et al. [17]). It will provide location information where available as well as an overview of the knowledge base, including hotspots of data collection and information gaps in our knowledge base and will be especially important to studies and management at larger spatial scales (i.e., watershed, regional, or global scales). This database will be useful for biodiversity conservation as well as research including improving valuation methods for river fish and fisheries to more accurately recognize the full breadth of provided services or for assessing the relative importance of river fisheries to human populations globally. These data are necessary to develop biomass models that can be used to predict how river fishery could change under different scenarios, particularly in the context of global change [18]. In doing so, river fish and fisheries can be better incorporated into decision making to support sustainable river fish and freshwater management. As recently described for North American inland fisheries, inland waters often have multiple public uses and management goals may be overlapping, conflicting, or mutually dependent [19]. Resolving these interactions depends on the availability of accurate data and models to predict current fishery production and forecasts given pending local, regional, and global changes.

\section{Identification of the topic}

The "Rome declaration: ten steps to responsible inland fisheries" [20] synthesized the results of the 2015 global conference on inland fisheries of nearly 250 scientists, policy makers, and members of the development community from more than 40 countries, into a list of ten key actions to help ensure sustainable inland fisheries. This declaration was emphatically endorsed by the member parties at the 2016 FAO committee on fisheries as a sign of growing recognition of the importance of inland freshwater fisheries in many countries. The first step in this list is to "improve the assessment of biological production" of inland fisheries. The work described in this protocol was identified as a principal need to address this critical knowledge gap and has been since refined by the research team. A companion study focused on inland lakes was conducted by other members who participated in the 2015 global conference [21]. Ultimately, the goal of the conference and its outcomes is to improve the sustainability of freshwater aquatic resources and to bring greater awareness of the value and sustainability challenges of inland fisheries around the world [20].

\section{Objective of the map}

This project aims to identify, collate, and describe information on the geographical distribution of river fish harvest. Relevant information consists of fisheriesdependent and fisheries-independent data on river fish, including where and how river fish were captured. Data on river fisheries harvest will be identified and collected using the systematic mapping method described below.

Systematic mapping provides a comprehensive, transparent, and objective method for collecting and describing the state and distribution of current knowledge on a topic [22]. Through systematic mapping, our research attempts to fill the river fisheries knowledge gap by aggregating river fishery data globally. We expect two products from this endeavor:

1. River fisheries database (available at no cost online through a USGS portal).

2. Systematic map of the state of river fisheries information (submitted for publication in this journal).

These products will provide an important data resource for researchers, policy makers, and managers of river fisheries and will be used for assessing variation and trends in river fisheries or for modeling production and predicting changes due to factors such as climate or land-water 
use change. This information may also be used as a basis for future quantitative systematic review questions related to the map findings, such as modeling changes in harvest over time or impacts from different harvest methods.

\section{Primary question}

What is the global distribution of river fisheries harvest?

This question targets information about the distribution and scale of an activity, so can be broken down into three main components using the "PIO" format; the population $(\mathrm{P})$, the intervention $(\mathrm{I})$, and the outcome $(\mathrm{O})$ per Table 1. In the case of this study, the intervention is actually an activity, though the question formation follows the same PIO format as interventions.

\section{Methods}

\section{Searches}

River list

The geographic scope of this initial systematic map targets 60 rivers around the world (Table 2). These rivers were identified by selecting (1) the largest rivers by drainage size that are currently flowing [23, 24], and (2) the most intensely harvested rivers according to the expert opinion of the authors as well as consultation with a subject matter expert (Cowx, University of Hull, pers. comm.). These criteria were used as a starting point to focus our global analysis on the largest and most intensely harvested rivers where data should be more readily available in comparison to smaller rivers or streams. Each river search will be conducted independently and the names of the rivers are used in the search process described below.

\section{Search terms}

Search terms were developed using keywords from fisheries articles then tested against a list of relevant articles from an independent literature review provided by a colleague (Cowx, University of Hull, pers. comm.). Additional file 1 describes the preliminary search process and provides the original search terms used for scoping. The final list of search terms reflects the need to include river names to target relevant terms given the broad scope of the research question. In some cases, the initial searches returned millions of results via Google Scholar and this

Table 1 Key elements of the primary review question

\begin{tabular}{ll}
\hline Population & Fish populations within river systems \\
\hline Intervention & $\begin{array}{c}\text { Capture of populations and communities of finfish for } \\
\text { food, income, or recreation [19] }\end{array}$ \\
Outcome & $\begin{array}{c}\text { Any reported distinct information on fish harvest biomass. } \\
\text { The targeted data include species, weight, time, location, } \\
\text { or changes in fish biomass }\end{array}$
\end{tabular}

strategy is aiming for a more targeted, relevant database consisting of hundreds of files. Additional search terms from the original test set did not increase the number of relevant articles returned from the search and were thus eliminated; however, the search string may be modified during the full searches as necessary. Search terms used for each river are provided in Additional file 1 and will be included as part of final project metadata and supplemental information.

All searches will be conducted in web browsers with cookies and browser history disabled and in private settings (e.g., using "incognito mode" in 'Google Chrome') to reduce bias generated by user-specific returns.

\section{Databases and search engines}

Table 3 provides a list of the databases, search engines, and organizational sites that will be searched. The large amount of grey literature sites (67) reflect the amount of practitioner-based research and data generated regarding inland fisheries. This list of databases, search engines, and sites was designed to return as comprehensive set of broad range results as possible by including both general search engines (i.e., Google Scholar), databases (i.e. Web of Science) and institutional specific databases [25]. Colleagues and participants of the global conference on inland fisheries also reviewed and suggested additions to the list to increase inclusivity of global regions. Organizations were selected based on involvement in river fisheries and potential for hosting relevant data because they are known by our team or collaborators to either collect or aggregate river fishery data.

The publication search engines and databases will be queried using the Boolean phrasing described below in the topic search categories. Web crawling software [26] will be used to query and collate data from the grey literature databases and regional/country organization sites. The first 100 returns from each grey literature site (Table 3) will be reviewed for inclusion. Google Scholar, Web of Science, and Scopus will be searched because of relatively little overlap between search results of the search engine and databases [27]. The China Knowledge Resource Integrated Database (CNKI) and Baidu Scholar will be used to target rivers where data or research may be presented in Mandarin. Proquest Aquatic Science Collection will also be included to capture reports and grey literature that may not be available through our directed grey literature searches.

\section{Search terms and languages}

Search engines and databases will be searched using the following terms and Boolean phrasing (" denotes a wildcard character to include multiple word endings). The list of search phrases is available in Additional file 1. 
Table 2 Target rivers as identified by Vörösmarty et al. [23, 24] and Cowx (pers. comm.)

\begin{tabular}{|c|c|}
\hline Continent & River Basin \\
\hline \multirow[t]{13}{*}{ Africa } & Chari $^{\mathrm{a}}$ \\
\hline & Congo/Zaire ${ }^{\mathrm{ab}}$ \\
\hline & Gambia $^{\mathrm{b}}$ \\
\hline & $J_{u b b a^{a}}$ \\
\hline & $\operatorname{Limpopo}^{a b}$ \\
\hline & Niger ${ }^{\mathrm{ab}}$ \\
\hline & Nile $^{\mathrm{ab}}$ \\
\hline & Okavango ${ }^{b}$ \\
\hline & Orange $^{a}$ \\
\hline & Rufiji ${ }^{b}$ \\
\hline & Senegalab \\
\hline & Volta ${ }^{b}$ \\
\hline & Zambeziab \\
\hline \multirow[t]{21}{*}{ Asia } & Amu-Darya $^{a}$ \\
\hline & Amurab \\
\hline & Ayrewaddy ${ }^{\mathrm{b}}$ \\
\hline & Brahmaputra \\
\hline & Chang Jiang/Yangtze ${ }^{a b}$ \\
\hline & Chao Phraya ${ }^{b}$ \\
\hline & Ganges $^{\mathrm{ab}}$ \\
\hline & Huang He/Yellowa \\
\hline & Indus $s^{a b}$ \\
\hline & Kolyma $^{\mathrm{a}}$ \\
\hline & Lena $^{\mathrm{ab}}$ \\
\hline & Mahakam ${ }^{b}$ \\
\hline & Mekong $^{\mathrm{ab}}$ \\
\hline & Ob/lrtysh ${ }^{\mathrm{ab}}$ \\
\hline & Pearl/Zhujiang/Canton ${ }^{b}$ \\
\hline & Red/Yuan/Hóng Héb \\
\hline & Salween River ${ }^{\mathrm{b}}$ \\
\hline & Shatt el Araba \\
\hline & Syr-Darya ${ }^{a}$ \\
\hline & Tarim $^{\mathrm{a}}$ \\
\hline & Yenisei $^{\mathrm{ab}}$ \\
\hline \multirow[t]{6}{*}{ Europe } & Danube ${ }^{a b}$ \\
\hline & Dnepr $^{a}$ \\
\hline & Don $^{\mathrm{a}}$ \\
\hline & Rhine $^{b}$ \\
\hline & $U_{r a l}{ }^{b}$ \\
\hline & $\operatorname{Volga}^{\mathrm{ab}}$ \\
\hline \multirow[t]{9}{*}{ North America } & Colorado (USA/Mexico) $)^{\text {ab }}$ \\
\hline & Columbia $^{a}$ \\
\hline & MacKenzie ${ }^{a}$ \\
\hline & Mississippi ${ }^{\mathrm{ab}}$ \\
\hline & Missourib \\
\hline & Nelson ${ }^{\mathrm{a}}$ \\
\hline & Rio Grande ${ }^{\mathrm{ab}}$ \\
\hline & St. Lawrence ${ }^{a}$ \\
\hline & Yukon ${ }^{\mathrm{ab}}$ \\
\hline
\end{tabular}

Table 2 continued

\begin{tabular}{ll}
\hline Continent & River Basin \\
\hline South America & Amazon $^{\mathrm{ab}}$ \\
& Colorado (Argentina) $^{\mathrm{a}}$ \\
& Magdalena $^{\mathrm{b}}$ \\
& Orinoco $^{\mathrm{ab}}$ \\
& Paranáab $^{\mathrm{ab}}$ \\
& Sao Francisco $^{\mathrm{b}}$ \\
& Tocantins $^{\mathrm{ab}}$ \\
& Great Artesian $^{\mathrm{a}}$ \\
Oceania & Murray-Darling $^{\mathrm{ab}}$ \\
& Sepik $^{\mathrm{b}}$ \\
\hline
\end{tabular}

a Vorosmarty et al. [23, 24]

b Expert opinion

river name (e.g., "Congo")

AND

river*

AND

fish* OR fisher* OR aquaculture

Example phrase: (Congo OR Zaire) AND river* AND (fish* OR fisher* OR aquaculture)

English is the dominant language for scientific publications [28], but we recognize the growing literature base in other prominent languages [29]. As such, searches will be conducted in English only for the publication databases and grey literature websites. Searches in Google Scholar will be conducted in English, Spanish, French, Portuguese, and Mandarin (Table 4) based on the primary languages spoken in the countries where the 60 major rivers flow. Scoping of search terms in the 5 non-English United Nations Languages plus the major languages spoken in countries containing selected rivers is located in Additional file 2 . We recognize that fisher* would be automatically included with the use of fish", but both fish" and fisher* are used because the words do not have the same root in non-English languages (Table 4).

\section{Estimating the comprehensiveness of the search}

Our search strategy was designed to provide a broad scope of results regarding river fisheries data to be as comprehensive as possible. Primary studies will be targeted while review papers will be used to identify primary studies and data. All articles gathered, including 
Table 3 Search sources

\begin{tabular}{lll}
\hline & Publication databases/search engines & Website \\
\hline 1 & Web of Science Core Collections & https://webofknowledge.com \\
2 & Google Scholar & https://scholar.google.com \\
3 & SciVerse Scopus $/ /$ www.info.sciverse.com & http://proquest.libguides.com/asfa \\
4 & Proquest Aquatic Science Collection & http://kns.cnki.net \\
6 & China Knowledge Resource Integrated Database & http://xueshu.baidu.com \\
\hline
\end{tabular}

\begin{tabular}{|c|c|c|}
\hline & Grey literature sites & Website \\
\hline 1 & A Rocha International & http://www.arocha.org \\
\hline 2 & BirdLife International & http://www.birdlife.org \\
\hline 3 & CARE International & http://www.care-international.org \\
\hline 4 & Caribbean Natural Resources Institute & http://www.canari.org \\
\hline 5 & Catholic Agency for Overseas Development (CAFOD) & http://www.cafod.org/uk \\
\hline 6 & Centre for Environment, Fisheries and Aquaculture Science & http://www.cefas.co.uk \\
\hline 7 & Centre for International Forestry Research (CIFOR) & http://www.cifor.org \\
\hline 8 & Conservation International & http://www.conservation.org/Pages/default.aspx \\
\hline 9 & Convention on Biological Diversity & http://www.cbd.int \\
\hline 10 & Department for International Development (DFID), UK & $\begin{array}{l}\text { http://www.gov.uk/government/organisations/department-for-inter- } \\
\text { national-development }\end{array}$ \\
\hline 11 & European Commission Joint Research Centre & http://www.ec.europa.eu/dgs/jrc \\
\hline 12 & European Fisheries and Aquaculture Research Organisation & http://www.efaro.eu \\
\hline 13 & FAO Fisheries and Aquaculture Department & http://www.fao.org/fishery/en \\
\hline 14 & Freshwater Ecoregions of the World & http://www.feow.org/globalmap \\
\hline 15 & Global Environment Facility & http://www.thegef.org \\
\hline 16 & Global Freshwater Biodiversity Atlas & http://atlas.freshwaterbiodiversity.eu \\
\hline 17 & $\begin{array}{l}\text { Intergovernmental Platform on Biodiversity and Ecosystem Services } \\
\text { (IPBES) }\end{array}$ & http://www.ipbes.net \\
\hline 18 & International Collective in Support of Fishworkers & https://igssf.icsf.net/index.php \\
\hline 19 & International Development Research Centre (IDRC) & https://www.idrc.ca \\
\hline 20 & International Institute for Environment and Development (IIED) & http://www.iied.org \\
\hline 21 & International Rivers & https://www.internationalrivers.org \\
\hline 22 & International Union for Conservation of Nature (IUCN) & http://www.iucn.org \\
\hline 23 & Marine Resources Assessment Group & http://www.mrag.co.uk \\
\hline 24 & North American Native Fishes Association & http://www.nanfa.org/links.shtml \\
\hline 25 & The Nature Conservancy & http://www.nature.org \\
\hline 26 & Organisation for Economic Co-operation and Development (OECD) & https://www.oecd.org \\
\hline 27 & Stockholm Environment Institute & https://www.sei-international.org \\
\hline 28 & United Nations Environment Programme & http://www.unep.org \\
\hline 29 & $\begin{array}{l}\text { United Nations Environment Programme-World Conservation Monitor- } \\
\text { ing Centre }\end{array}$ & http://www.unep-wcmc.org \\
\hline 30 & United Nations Development Programme & http://www.undp.org \\
\hline 31 & United States Agency for International Development (USAID) & http://www.usaid.gov \\
\hline 32 & Wetlands International & https://www.wetlands.org \\
\hline 33 & Wildlife Conservation Society (WCS) & http://www.wcs.org \\
\hline 34 & World Bank & http://www.worldbank.org \\
\hline 35 & WorldFish & http://www.worldfishcenter.org \\
\hline 36 & World Resources Institute & http://www.wri.org \\
\hline 37 & Worldwide Wildlife Fund (WWF) & http://wwf.panda.org \\
\hline
\end{tabular}


Table 3 continued

\begin{tabular}{|c|c|c|}
\hline & Country/regional sites & Website \\
\hline 1 & African Caribbean, and Pacific Group of States Fish II Programme & http://acpfish2-eu.org \\
\hline 2 & ADB, African Development Bank & http://www.afdb.org \\
\hline 3 & Australia_Commonwealth Scientific and Industrial Research Organisation & http://www.csiro.au \\
\hline 4 & Biodiversity Information System for Europe & http://biodiversity.europa.eu/topics/species/freshwater-fishes \\
\hline 5 & Canada_Federal Science Library (Combines ECC, DFO, and WAVES databases) & http://science-libraries.canada.ca/eng/home/ \\
\hline 6 & Denmark—Denmark-Danish Centre for Environment and Energy & http://dce.au.dk \\
\hline 7 & England-Centre for Environment, Fisheries and Aquaculture Science & http://www.cefas.defra.gov.uk \\
\hline 8 & Eurofish & http://www.eurofish.dk \\
\hline 9 & Finland_-Natural Resource Institute Finland & http://www.luke.fi \\
\hline 10 & Finland_Finland's environmental administration & http://www.environment.fi \\
\hline 11 & Germany_Leibniz Institute of Freshwater Ecology and Inland Fisheries, IGB & http://www.igb-berlin.de \\
\hline 12 & Germany_Senckenberg & http://www.senckenberg.de \\
\hline 13 & India_Central Institute of Fisheries Technology & http://www.cift.res.in/innercontent.php?contentid=NTAx \\
\hline 14 & Lake Tanganyika Authority & http://lta.iwlearn.org \\
\hline 15 & Lake Victoria Basin Commission & https://www.lvbcom.org \\
\hline 16 & Lake Victoria Fisheries Organization & http://www.lvfo.org \\
\hline 17 & Murray-Darling Basin Authority & http://www.mdba.gov.au \\
\hline 18 & Myanmar/Thailand/Laos/Vietnam-Mekong River Commission & http://www.mrcmekong.org \\
\hline 19 & Netherlands Institute of Ecology & http://www.nioo.knaw.nl \\
\hline 20 & Netherlands_-Royal Netherlands Institute of Sea Research & http://www.nioz.nl/home_en \\
\hline 21 & Nile Basin Initiative & http://www.nilebasin.org \\
\hline 22 & NDF, Nordic Development Fund & http://www.ndf.fi \\
\hline 23 & Norway—Norwegian Institute for Water Research (NIVA) & http://www.niva.no \\
\hline 24 & South African Council for Science and Industrial Research & https://www.csir.co.za \\
\hline 25 & Sweden—IVL Swedish Environmental Research Institute & http://www.ivl.se \\
\hline 26 & Sweden_-Swedish Agency for Marine and Water Management & http://www.havochvatten.se \\
\hline 27 & USA-BISON & https://bison.usgs.gov/\#home \\
\hline 28 & USA_Great Lakes Fishery Commission & http://www.glfc.org \\
\hline 29 & USA/Canada_US Fish and Wildlife Service & https://www.fws.gov \\
\hline 30 & USA—National Marine Fisheries Service & http://www.nmfs.noaa.gov \\
\hline
\end{tabular}

Table 4 Search terms by language

\begin{tabular}{|c|c|c|c|c|}
\hline Language & Term 1 & Term 2 & Term 3 & Term 4 \\
\hline Chinese (Mandarin) & 河 & 鱼 & 渔 & 养殖渔业 \\
\hline English & river* & fish $^{*}$ & fisher* & Aquaculture \\
\hline French & $\begin{array}{l}\text { riviere* } \\
\text { fleuve* }\end{array}$ & poisson* & pêche* & Aquaculture \\
\hline Portuguese & rio* & peixe ${ }^{*}$ & pescado* & $\begin{array}{r}\text { Hidrocultura/ } \\
\text { acuicultura }\end{array}$ \\
\hline Spanish & río* & pez $z^{*}$ & pescado* & Acuicultura \\
\hline
\end{tabular}

review papers, will be included in the final reference database. We recognize that a large amount of data may be reported only through grey literature or stored on organizational sites. As such, our search strategy includes 37 grey literature databases and 30 regional or country sites (Table 3). Further sites may be added as revealed by the search results to be potentially relevant.

For the search engine (Table 3), an accumulation or discovery curve strategy will be used to assess the return on investment for continuing through search results. As each river constitutes a distinct search, this process will be conducted for each river search, within each distinct database. Because this process includes a unique search for each river in each database, duplicates of the same articles will be collected. These will be screened during the "Article screening and study inclusion criteria" described below, but also allow calculation of overlap between databases. The process is similar to that used for recording the cumulative number of species in a particular environment as a function of search effort [30]. As new relevant articles are collected and entered into the database, the total number of potentially relevant articles 
per 100 search results will be calculated and plotted. The search continues, considering new articles in groups of 100 returns at a time to plot potentially relevant articles per unit of search effort. This step will be conducted during the screening process described below. In this way, the number of new, potentially relevant returns that will be discovered with continued effort can be estimated. Once the asymptote of the curve has been reached (no new relevant articles revealed for 3 groups of 100 search returns evaluated), searching in this data base will discontinue [30].

\section{Article screening and study inclusion criteria Screening}

Article screening will occur in two steps. First, the title and abstract will be reviewed for potentially relevant articles. Second, the full text will be read from those screened during step one for relevant data. Initial screening will be conducted by two members of the research team until consistency in screening is established between screeners. Consistency will be measured using the Kappa statistic, which measures the degree of agreement between two coders [31]. This systematic map process will implement two to four coders. All coders will search and screen the same river and the kappa statistic will be calculated. Criteria and differences between included article sets will be reviewed until kappa statistic values return moderate to high values, $>0.5$ [32]. Meetings to discuss search strategy and study inclusion will occur at regular intervals to maintain consistency throughout the search and study inclusion.

The inclusion criteria described below will be applied during the search process for collecting potentially relevant articles and then screening collected articles for inclusion in the final geodatabase. The number of all included and excluded articles will be recorded at each stage of the screening and study inclusion process per the PRISMA flow chart [33].

\section{Study inclusion criteria}

All potentially relevant citations selected during the search process will be saved into a reference manager or systematic review software (such as Zotero or Mendeley) for full text review. Articles that are not open access will be requested through inter-library loan or via university library subscriptions from university-affiliated researchers on our team. Articles will be selected from the search if they meet all the following criteria, erring on the side of inclusion. At the first screening step, article will be selected if it meets the first two criteria and if the title and abstract indicates the article contains species-specific and location-specific information about fish biomass. After duplicates are removed, title and abstracts will be reviewed and studies excluded based on the following criteria:

- Not river related.

- No information provided on fish biomass.

- No or insufficient location information provided. Sufficient location information includes information (text description, coordinates, or a map) to pinpoint a location or specific area on a map where fish were extracted.

- Insufficient methodological information to determine how data was acquired.

During the second screening step of the full text, only those studies that do actually contain species-specific and location-specific information about fish biomass will be selected for inclusion.

- Is primary research, a review, a dataset, a book, or a report

- Was published between 1950 and 2016.

- The start date of 1950 was selected because it is also the first year that FAO provides global fisheries statistics [13].

- The article contains species-specific and locationspecific information about fish biomass.

In order to be included in the final database and map, a study must meet all of the following criteria:

Relevant subjects River or river aquaculture fish species (as identified by Fishbase.org).

Relevant interventions Capture/extraction of populations and communities of fish for food, income, or recreation.

Relevant outcomes Fish biomass extraction from rivers. This data will include different units for weight, and different articles may report data at different spatial and temporal scales as well as have different definitions for catch, harvest, yield, production, etc. The original data will be extracted from the articles and then, when possible, converted to consistent units for analysis as described below in the "Data coding strategy" and Table 5.

Relevant study designs Quantitative research including experimental, quasi-experimental, observational studies will be included. Secondary studies including literature reviews and systematic reviews will be used to identify additional primary sources of information.

The original source of the data and type of organization (non-governmental, governmental, etc.) will be included 
Table 5 Field names and definitions for data collected through the systematic map process

\begin{tabular}{|c|c|c|}
\hline Field name & Field definition & Field type \\
\hline Ref_ID & DOI or assigned reference number & $\operatorname{VARCHAR}(25)$ \\
\hline RIVERID & $\begin{array}{l}\text { (Metadata) artificial sequence number, linked to metadata table. RIVERID is derived from on Natu- } \\
\text { ralEarth Rivers Database }\end{array}$ & $\operatorname{NUMBER}(6)$ \\
\hline RIVER_NAME & River name & VARCHAR2(150) \\
\hline RIVER_ZONE_ID & $\begin{array}{l}\text { Segment ID from the river zones. these zones were defined in a separate modeling analysis based } \\
\text { on a k-mean plus cluster algorithm where cluster were derived based on six different bio-physical } \\
\text { parameters of the rivers. A separate manuscript regarding this modeling effort is under preparation }\end{array}$ & $\operatorname{NUMBER}(15)$ \\
\hline FISHCATCH_ID & Fish_Catch_record sequence number (unique) & NUMBER(6) \\
\hline BEG_DATE & Beginning date of fish data. Format: month/year example: 06/2016 & DATE \\
\hline END_DATE & End date of fish data. Format: month/year example: 06/2016 & DATE \\
\hline EST_DATE & Is the date estimated? ( $1=$ yes, $2=$ no $)$ & $\operatorname{NUMBER}(1)$ \\
\hline FISH_CATCH_LAT & Latitude coordinate of fish catch in decimal degree & $\operatorname{NUMBER}(15,2)$ \\
\hline FISH_CATCH_LONG & Longitude coordinate of fish catch in decimal degree & $\operatorname{NUMBER}(15,2)$ \\
\hline FISH_CATCH_LOCATION & Original coordinate or location data from the reference & VARCHAR2(150) \\
\hline LOCATION_MAP & Is there a map showing the location of data collection? (1 = yes, $2=$ no) & $\operatorname{NUMBER}(1)$ \\
\hline FISH_CATCH_SPECIES & $\begin{array}{l}\text { Species full Latin name. Enter "Mixed Catch" if specific species names are not provided. Example: } \\
\text { Schizodon fasciatus }\end{array}$ & NUMBER(8) \\
\hline FISH_CATCH_COUNT & Number of individual fish caught. Enter N/A if number is not available & NUMBER(8) \\
\hline FISH_SPECIES_TYPE & $\begin{array}{l}\text { Select type of species ( } 1=\text { native, } 2=\text { non-native, } 3=\text { article does not specify). If a report combines } \\
\text { multiple fisheries, catch from each fishery will be recorded as separate entries }\end{array}$ & $\operatorname{NUMBER}(1)$ \\
\hline FISH_SPECIES_INTRO_YR & $\begin{array}{l}\text { If introduced species then the year this species introduced in this river system, as determined by } \\
\text { fishbase.org }\end{array}$ & NUMBER(4) \\
\hline FISH_CATCH_TYPE & $\begin{array}{l}\text { Select the reason for fish capture }(1=\text { artisanal, } 2=\text { commercial, } 3=\text { recreational, } 4=\text { scientific study, } \\
5=\text { subsistence, } 6=\text { aquaculture, } 7=\text { others })\end{array}$ & $\operatorname{NUMBER}(1)$ \\
\hline FISH_CATCH_WT & $\begin{array}{l}\text { The numeric value for the weight of the fish catch. The unit of weight is recorded in the field FISH_ } \\
\text { CATCH_UNIT }\end{array}$ & $\operatorname{NUMBER}(15,2)$ \\
\hline FISH_CATCH_UNIT & Select the weight unit reported by the article & $\operatorname{VARCHAR2}(5)$ \\
\hline FISH_CATCH_KG & Fish biomass, in kg. Calculated from field "FISH_CATCH_WT" & $\operatorname{NUMBER}(15,2)$ \\
\hline SAMPLED_AREA & What area was sampled (include units) & $\operatorname{NUMBER}(8,2)$ \\
\hline FISH_CATCH_BY_AREA & Fish biomass, in kg/ha or X unit & $\operatorname{NUMBER}(15,2)$ \\
\hline TOTAL_BIOMASS & $\begin{array}{l}\text { The numeric value for the total biomass captured (including fish and other species). Enter N/A if not } \\
\text { available }\end{array}$ & $\operatorname{NUMBER}(15,2)$ \\
\hline TOTAL_BIOMASS_UNIT & Select the weight unit reported by the article & VARCHAR2(5) \\
\hline TOTAL_BIOMASS_KG & Total biomass captured in the haul in KG (including fish and other species). Enter N/A if not available & $\operatorname{NUMBER}(15,2)$ \\
\hline GEAR_TYPE & $\begin{array}{l}\text { Select the type of gear used to capture the fish species }(1=\operatorname{trawl}, 2=\text { net, } 3=\operatorname{traps}, 4=\text { line, } \\
5=\text { electrofishing, } 6=\text { other })\end{array}$ & VARCHAR2(150) \\
\hline GEAR_SIZE & Numerical value for the gear size & $\operatorname{NUMBER}(8,2)$ \\
\hline GEAR_SIZE_UNIT & Select the gear size unit reported by the article & VARCHAR2(150) \\
\hline GEAR_SIZE_cm & Mesh size or gear size in centimeters & $\operatorname{NUMBER}(8,2)$ \\
\hline FISHING_EFFORT_UNIT & Number of boats or gears used for the survey & $\operatorname{NUMBER}(8)$ \\
\hline FISHING_EFFORT_DURATION & Number of hours or days spend in fishing (days as 24 h) & $\operatorname{NUMBER}(8)$ \\
\hline
\end{tabular}

in the final database. A list of articles excluded at full text review with reasons for exclusion will be provided.

\section{Study quality assessment}

Because of variation in fish harvest methods and differing purpose for data collection in peer-reviewed and grey literature, critical appraisal will not be applied to this systematic map. However, descriptive and demographic information about researchers and data collection will be captured as they may be pertinent for how the data are used in modeling projects or estimations. Notes regarding the methodological descriptions will also be collected, including reliability of sources.

\section{Data coding strategy}

The following information will be collected from each article, when available. Other categories or target information may be added during the search process. 


\section{Capture effort and methods fields}

Fishing effort, gear type and size, vessel type and size, sampled area and location.

\section{Sector fields}

Subsistence, commercial, aquaculture, recreation, research, funding source.

\section{Information type fields}

Primary information (i.e., the report authors collected the information themselves), Secondary information; article reports data collected by another party.

\section{Map fields}

Author affiliations, research question or objective, outcome or conclusion, replication present or absent, control present or absent, review (R), before/after (BA), comparator/intervention (CI), before/after/comparator/ intervention (BACI), randomized controlled trial (RCT), objective or purpose of data collection.

Regarding the spatial component of fish biomass extraction, this information will consist of point locations, sets of point locations, areas, general descriptions, and river or watershed level scales. If the specific area cannot be determined from the information provided, that article will not meet study inclusion criteria and will be excluded from the final geodatabase. All other data will be included in the format provided by the original documentation. The final geodatabase will consist of point, multi-point, polygon, and multi-polygon shapefiles. The original spatial description, map, or coordinate information will be provided in the final geodatabase along with the spatial information. Changes in fish biomass over time or time-series data will include individual entries for each time point.

Intercoder reliability will be established by comparing extracted data between researchers. Table 5 provides the field names and definitions of the data targeted for extraction from the search results. All persons contributing to data collection will be provided the same set of 20 articles and the actual data extracted will be compared. Discrepancies in collected data will be discussed and assessed until data collection is consistent. Other types of data may be added as identified by the search process. Data from these sources will then be synthesized into a geodatabase.

\section{Study mapping and presentation}

The systematic map database will be presented as a geodatabase that will be open-access and hosted by USGS Sciencebase. The geodatabase will be available as both a file geodatabase and a series of folders. All files within the geodatabase will consist of shapefiles, which are not proprietary. This systematic map protocol will accompany the geodatabase as metadata. Additionally, a systematic map describing the data collection process and results of the search. A geographic map of data density and data collected will review the distribution of information to identify knowledge gaps or concentrations of information and also address the temporal scale of available information. Understanding the distribution of current information can help target future studies to fill these gaps and reduce redundant data collection. This information could also be used to frame systematic review questions and research regarding river fisheries.

\section{Additional files}

Additional file 1. Search Terms Scoping. Information regarding the original search terms and scoping methods used to determine proposed search terms in the main manuscript.

Additional file 2. Languages Scoping. Description of methods used to determine the proposed search languages in the main manuscript.

\section{Authors' contributions}

CLR led map protocol development and will oversee literature search and data extraction. ZB, AL, and WT conceptualized the original research project. YCK provides expertize in Mandarin language and inland fisheries research in Asia. All authors contributed to protocol design, manuscript writing. All authors read and approved the final manuscript.

\section{Author details}

${ }^{1}$ Department of Environmental Science and Policy, George Mason University, 4400 University Dr., Fairfax, VA 22033, USA. ${ }^{2}$ US Geological Survey, National Climate Change and Wildlife Science Center, 12201 Sunrise Valley Drive, MS-516, Room 2A128A, Reston, VA 20192, USA. ${ }^{3}$ Environmental and Sustainability Studies Program, University of Northern Colorado, 501 20th St., Greeley, CO 80639, USA. ${ }^{4}$ Department of Fisheries and Wildlife, Center for Systems Integration and Sustainability, Michigan State University, 115 Manly Miles Building, 1405 South Harrison Rd., East Lansing, Ml 48823, USA. ${ }^{5}$ US Geological Survey, Great Lakes Science Center, 1451 Green Rd, Ann Arbor, MI 48105, USA.

\section{Acknowledgements}

We thank lan Cowx (University of Hull), Rachel Ainsworth (University of Hull), and NCCWSC staff for their assistance with refining this search methodology. We also thank Jessica Taylor for an internal USGS review, anonymous journal-selected reviewers, and the journal editors for their constructive feedback to improve this manuscript. Any use of trade, firm, or product names is for descriptive purposes only and does not imply endorsement by the US. Government. Its content is deliberative and predecisional, so it must not be disclosed or released by reviewers. Because the manuscript has not yet been approved for publication by the US Geological Survey (USGS), it does not represent any official USGS finding or policy.

\section{Competing interests}

The authors declare that they have no competing interests. If a reviewer is an author on a potentially relevant article, he or she will not be involved in the decisions regarding the inclusion of the article in the database.

Availability of data and materials Not applicable.

Consent for publication

Not applicable. 
Ethics approval and consent to participate

Not applicable.

\section{Funding}

This work was funded by the US Geological Survey's National Climate Change and Wildlife Science Center (NCCWSC).

\section{Publisher's Note}

Springer Nature remains neutral with regard to jurisdictional claims in published maps and institutional affiliations.

Received: 24 May 2017 Accepted: 26 October 2017

Published online: 04 December 2017

\section{References}

1. Lynch AJ, Cooke SJ, Deines AM, Bower SD, Bunnell DB, Cowx IG, et al. The social, economic, and environmental importance of inland fish and fisheries. Environ Rev. 2016;24:115-21. https://doi.org/10.1139/er-2015-0064.

2. Youn SJ, Taylor WW, Lynch AJ, Cowx IG, Douglas Beard T, Bartley D, et al. Inland capture fishery contributions to global food security and threats to their future. Glob Food Secur. 2014;3:142-8. https://doi.org/10.1016/j. gfs.2014.09.005

3. Orr S, Pittock J, Chapagain A, Dumaresq D. Dams on the Mekong River: lost fish protein and the implications for land and water resources. Glob Environ Chang. 2012;22:925-32. https://doi.org/10.1016/j. gloenvcha.2012.06.002

4. Dudgeon D, Arthington AH, Gessner MO, Kawabata Z-I, Knowler DJ, Lévêque C, et al. Freshwater biodiversity: importance, threats, status and conservation challenges. Biol Rev Camb Philos Soc. 2006;81:163-82. https://doi.org/10.1017/S1464793105006950.

5. Cooke SJ, Allison EH, Beard TD, Arlinghaus R, Arthington AH, Bartley DM, et al. On the sustainability of inland fisheries: finding a future for the forgotten. Ambio. 2016:45:753-64.

6. Mills DJ, Westlund L, de Graaf G, Kura Y, Willman R, Kelleher K. Underreported and undervalued: small-scale fisheries in the developing world. Small-Scale Fish Manag Framw Approach Dev World. 2011. https://doi. org/10.1079/9781845936075.0001.

7. Welcomme RL. An overview of global catch statistics for inland fish. ICES J Mar Sci. 2011;68:1751-6.

8. Cooke SJ, Lapointe NWR, Martins EG, Thiem JD, Raby GD, Taylor MK, et al. Failure to engage the public in issues related to inland fishes and fisheries: strategies for building public and political will to promote meaningful conservationa. J Fish Biol. 2013;83:997-1018.

9. FAO. Methods of resource investigation and their application. In: Manual of fisheries science. http://www.fao.org/docrep/003/F0752E/F0752E00. HTM\#toc.

10. Hortle KG. Fisheries of the Mekong River Basin. In: The Mekong. Biophysical environment of a transboundary river. New York: Elsevier; 2009. p. 197-249. https://doi.org/10.1016/B978-0-12-374026-7.00009-7.

11. Hortle KG. Consumption and the yield of fish and other aquatic animals from the Lower Mekong Basin. MRC Tech Pap. 2007;16:87. http://www. mrcmekong.org/assets/Publications/technical/tech-No16-consumptionn-yield-of-fish.pdf.

12. Coates D. Inland capture fishery statistics of Southeast Asia : current status and information needs. Bangkok: RAP publication; 2002.

13. FAO. Statistics Introduction. 2017. http://www.fao.org/fishery/statistics/ en. Accessed 29 Mar 2017

14. Bartley DM, De Graaf GJ, Valbo-Jørgensen J, Marmulla G. Inland capture fisheries: status and data issues. Fish Manag Ecol. 2015;22:71-7.

15. Martell S, Froese R. A simple method for estimating MSY from catch and resilience. Fish Fish 2013;14(4):504-514.

16. Pauly D, Zeller D. Catch reconstructions reveal that global marine fisheries catches are higher than reported and declining. Nat Commun. 2016:7:10244. https://doi.org/10.1038/ncomms10244.

17. Chassot E, Bonhommeau S, Dulvy N, Mélin F, Watson R, Gascuel D, et al. Global marine primary production constrains sheries catches. Ecology. 2010;13:495-505.
18. Brander KM. Global fish production and climate change. Proc Natl Acad Sci USA. 2007;104:19709-14.

19. Lynch AJ, Cooke SJ, Kao Y-C, Lorenzen K, Song AM, Allen MS, et al. Grand challenges in the management and conservation of North American inland fishes and fisheries. Fisheries. 2017:42:115-27.

20. Taylor WW, Bartley DM. Call to action-the "Rome declaration": ten steps to responsible inland fisheries. Fisheries. 2016;41:269. https://doi.org/10.108 0/03632415.2016.1183993.

21. Deines AM, Bunnell DB, Rogers MW, Bennion D, Woelmer W, Sayers MJ, et al. The contribution of lakes to global inland fisheries harvest. Front Ecol Environ. 2017:15:293-8.

22. James KL, Randall NP, Haddaway NR. A methodology for systematic mapping in environmental sciences. Environ Evid. 2016;5:7. https://doi. org/10.1186/s13750-016-0059-6.

23. Vörösmarty CJ, Fekete BM, Meybeck M, Lammers RB. Geomorphometric attributes of the global system of rivers at 30-min spatial resolution. J Hydrol. 2000;237:17-39.

24. Vorosmarty CJ, Fekete BM, Meybeck M, Lammers RB. Global system of rivers: its role in organizing continental land mass and defining land-toocean linkages. Glob Biogeochem Cycles. 2000;14:639-54.

25. Haddaway NR, Collins AM, Coughlin D, Kirk S. The role of Google Scholar in evidence reviews and its applicability to grey literature searching. PLoS ONE. 2015;10:1-17

26. Haddaway NR, Collins AM, Coughlin D, Kirk S. A rapid method to increase transparency and efficiency in web-based searches. Environ Evid. 2017;6:1. https://doi.org/10.1186/s13750-016-0079-2.

27. Haddaway NR, Bayliss HR. Shades of grey: two forms of grey literature important for reviews in conservation. Biol Conserv. 2015;191:827-9. https://doi.org/10.1016/j.biocon.2015.08.018.

28. Ammon U. The dominance of English as a language of science: effects on other languages and language communities. Berlin: Walter de Gruyter; 2001.

29. van Weijen D. The language of (future) scientific communication. Res Trends. 2012;7-9. http://www. researchtrends.com/issue-31-november-2012/ the-language-of-future-scientific-communication/.

30. Ugland KI, Gray JS, Ellingsen KE. The species-accumulation curve and estimation of species richness. J Anim Ecol. 2003:72:888-97.

31. Cohen J. A coefficient of agreement for nominal scale. Educ Psychol Meas. 1960:20:37-46.

32. CEE. Guidelines for systematic reviews in environmental management. Version 42. 2013;80. http://www.environmentalevidence.org/ Documents/Guidelines/Guidelines4.2.pdf

33. Liberati A, Altman DG, Tetzlaff J, Mulrow C, Gøtzsche PC, loannidis JPA et al. The PRISMA statement for reporting systematic reviews and metaanalyses of studies that evaluate health care interventions: explanation and elaboration. PLoS Med. 2009;6:e1000100.

\section{Submit your next manuscript to BioMed Central and we will help you at every step:}

- We accept pre-submission inquiries

- Our selector tool helps you to find the most relevant journal

- We provide round the clock customer support

- Convenient online submission

- Thorough peer review

- Inclusion in PubMed and all major indexing services

- Maximum visibility for your research

Submit your manuscript at www.biomedcentral.com/submit
C BioMed Central 